\title{
Emergências médicas em consultório odontológico: implicações éticas e legais para o cirurgião-dentista
}

\author{
Medical emergencies in dentistry: ethical and legal implications for dentists
}

POLIZELI, Amanda Felis ${ }^{1}$; ROLIM, Valéria Cristina Lopes de Barros ${ }^{2}$; FERNANDES, Samuel Lucas ${ }^{3}$; BOER, Nagib Pezati ${ }^{4}$

1. Graduada em Odontologia, Universidade Brasil, Fernandópolis, SP, Brasil.
2. Mestre em Bioengenharia. Professora da Universidade Brasil, Fernandópolis, SP, Brasil.
3. Mestre em Ciências Odontológicas Aplicadas. Professor da Universidade Brasil, Fernandópolis, SP, Brasil.
4. Doutor em Ciências da Saúde. Professor da Universidade Brasil, Fernandópolis, SP, Brasil.

Endereço para correspondência:

Samuel Lucas Fernandes

Faculdade de Odontologia de Bauru - USP

Disciplina de Endodontia

Alameda Doutor Octávio Pinheiro Brisolla, 9-75

17012-901 - Bauru - São Paulo - Brasil

E-mail: samuel.lukas.usp@gmail.com

Recebido: 26.10.2017

Aceito: 12.11.2017

\section{RESUMO}

O cirurgião-dentista, em seu cotidiano laborativo está intimamente ligado com o risco de ocorrer em seu consultório uma emergência médica. Mesmo não sendo comuns, essas emergências podem acontecer em ambiente odontológico. Podem acometer qualquer indivíduo, antes, durante ou após a intervenção odontológica. Desta maneira além dos acometimentos relativos à saúde de seus pacientes o cirurgião-dentista também está às vistas com as implicações legais que estas emergências geram para o profissional, tendo de se ater a toda responsabilidade que tem para com o paciente, no sentido da promoção de saúde, e no sentido legal. O cirurgião-dentista deve estar preparado para todos os eventos que possam a vir a acontecer em seu ambiente de trabalho. Uma avaliação do estado geral de saúde de seus pacientes, adoção de medidas preventivas e jurídicas, dá maior segurança no atendimento, bem como, as implicações éticas e legais as quais estão submetidos os cirurgiões-dentistas. Através da pesquisa bibliográfica procuramos alertar e orientar o cirurgião-dentista sobre as principais situações de emergência médica que poderão ocorrer no consultório odontológico. Apresentaremos os sinais e sintomas das principais emergências médicas e quais as formas de tratamento ou os primeiros cuidados que deverão ser tomados para a manutenção da vida do paciente. A maioria dos estudos aponta uma elevação no número de emergências médicas, associada a uma grande insegurança dos cirurgiões-dentistas no enfrentamento destas situações emergenciais.

Palavras-chave: Emergências. Consultórios odontológicos. Odontólogos.

\section{ABSTRACT}

The dental surgeon in his daily work intimately connected with the risk of a medical emergency occurring in his office. Even though they are not common, these emergencies can happen in a dental environment. They can affect any individual, before, during or after the dental intervention. In this way, in addition to the health concerns of his patients, he dental surgeon also exposed to the legal implications that these emergencies generate for the professional, having to hold all responsibility he has towards the patient, in the sense of promoting health, and in the legal sense. The dental surgeon must prepared for any events that may happen in his work environment. An evaluation of the general health of their patients, adoption of preventive and legal measures, gives greater security in the care, as well as the ethical and legal implications that submitted to dentists. Through bibliographic research, we seek to alert and guide the dental surgeon about the main emergencies that may occur in the dental office. We will present the signs and symptoms of the major medical emergencies and the forms of treatment or the first care that should taken to maintain the life of the patient. Most of the studies point to an increase in the number of medical emergencies, associated with a great uncertainty among dentists in facing these emergencies.

Keywords: Emergencies. Dental offices. Dentists. 


\section{INTRODUÇÃO}

Com o avanço da medicina e elevação da expectativa de vida, vem ocorrendo aumento da diversidade de pacientes que procuram por tratamento odontológico. Tais indivíduos que antes não frequentavam o consultório odontológico por restrições médicas, estão cada dia mais preocupados com sua saúde bucal ${ }^{1}$.

Muitas das emergências que acontecem em consultório odontológico podem ser prevenidas através do uso de uma anamnese adequada, para uma criteriosa avaliação da história médica do paciente, e também por uma avaliação física. Nos Estados Unidos, $10 \%$ das mortes não acidentais que ocorrem a cada ano, são súbitas e inesperadas, e ocorrem supostamente em pessoas saudáveis. Este fato fez com que cada cirurgião-dentista e equipe, ficassem mais vigilantes ${ }^{2}$.

$\mathrm{O}$ evento emergencial consiste em uma ocorrência de agravo à saúde, com risco iminente de vida ou que cause intenso sofrimento ao paciente. É um estado imprevisto e requer uma ação imediata para a preservação da vida. Pode acontecer com qualquer pessoa, a qualquer momento e em qualquer lugar. Portanto, o cirurgião-dentista tem que estar apto e seguro para o manejo de uma emergência ${ }^{3}$.

As quatro principais situações emergenciais tempodependente são: parada cardiorrespiratória, infarto agudo do miocárdio, acidente vascular cerebral e obstrução das vias aéreas ${ }^{4}$.

$\mathrm{O}$ atendimento satisfatório do paciente é a meta precípua de profissionais que estão realmente engajados no binômio saúde/doença, por isso, é que se faz necessário, não só o conhecimento das principais situações emergenciais em todos os seus aspectos, como também a formação de uma consciência única de aquisição de conhecimentos a respeito de Suporte Básico de Vida. Existe na Odontologia o amparo legal para a atuação do cirurgião-dentista frente às emergências que possam ocorrer em seu consultório odontológico. A Lei 5081/66 que regulamenta o exercício profissional diz em seu Artigo $6^{\circ}$, Inciso VIII: "Prescrever e aplicar medicação de urgência no caso de acidentes graves que comprometam a vida e a saúde do paciente" ${ }^{5}$.

Dados recentes mostram que a maioria dos profissionais de odontologia não se sente segura e capacitada para o correto atendimento de uma emergência, ficando assim dependente da presença médica para socorrer o paciente 5 .

Em qualquer situação emergencial o cirurgião-dentista deve seguir um roteiro de tratamento que consiste em: o Suspender o tratamento e avaliar o estado de consciência; o Assegurar que o paciente tenha as vias aéreas desobstruídas; o Observar a frequência e o tipo de respiração; o Verificar o pulso arterial e suas características; o Aferir a pressão arterial; o Se o paciente estiver inconsciente iniciar manobras de reanimação ${ }^{6}$.

A responsabilidade civil do profissional do cirurgião- dentista cabe a qualquer ato que o mesmo pratique em sua carreira e a emergência não é uma situação que está fora desta jurisdição. Além da esfera civil, o profissional também pode estar enquadrado na esfera criminal, esta por sua vez possui pressupostos mais rígidos do que a civil. Para que se comprove a culpa do profissional, seus atos devem estar incluídos nas modalidades de imprudência, imperícia ou negligência, e poderá ser condenado pelos delitos de lesões corporais culposas ou mesmo por homicídio doloso. A responsabilidade civil decorre normalmente de um dano causado por um ato culposo do agente, mas para que isso seja comprovado deve-se ter: o dano indenizável, a conduta culposa e o nexo de causalidade ${ }^{7}$.

A temática revela-se pertinente, sobretudo quando se inicia a prática clínica em consultório dentista. A formação teórica em situações de emergência, nem sempre acompanhada por treino prático dá lugar à discussão científica. $\mathrm{O}$ cirurgião-dentista, nem sempre se sente apto para solucionar uma situação em emergência que possa estar sujeito, caso esta ocorra no consultório dentário, sendo o principal responsável.

Este artigo tem como objetivo uma revisão bibliográfica sobre as emergências médicas, em ambiente odontológico, evidenciando quais as principais problemáticas e formas de atuação. Enfatizando ainda o papel do dentista, da equipe clínica e quais os pontos importantes para a sua capacidade de resposta a uma situação deste gênero. Questões éticas e legais são também tidas em conta, uma vez que o cirurgião-dentista é o responsável máximo sobre a saúde do paciente no consultório dentário.

Foi realizado um levantamento bibliográfico através de artigos, e no Google acadêmico. A estratégia de busca utilizou os seguintes descritores nos idiomas português, espanhol e inglês, através dos Descritores em Ciências da Saúde (DeCS): "Emergências médicas odontológicas"; "Equipamentos"; "Identificação"; "Tratamento"; "Implicações éticas e legais".

Assim, procuraremos através da revisão bibliográfica alertar e auxiliar os alunos e profissionais no que diz respeito aos sinais e sintomas, o diagnóstico e os primeiros procedimentos que competem ao cirurgião-dentista frente às principais situações de emergência médica na clínica odontológica.

\section{REVISÃO DE LITERATURA}

\section{Preparação da Clínica Dentária}

Durante um tratamento dentário pode ocorrer qualquer tipo de emergência médica, o que faz com que consideremos como boa prática, que o cirurgião-dentista e 
auxiliar esteja apto a lidar com este tipo de situações, bem como uma preparação adequada do consultório, no que diz respeito a equipamentos e fármacos. Este conjunto de equipamentos deve ter em conta a capacidade do dentista no seu manuseamento, as obrigações da Entidade Reguladora de Saúde, o tipo de paciente que recorre, mais frequentemente, à consulta (por exemplo, crianças, pessoas portadoras de necessidades especiais) e a área geográfica. Com efeito deve ter-se em consideração o tempo que os meios de socorro precisam para chegar ao consultório ${ }^{8}$.

Em 2001, foi publicado em Diário da República, o Decreto-Lei n $^{\circ} 233 / 2001$ de 25 de agosto (Artigo 26) ${ }^{9}$, onde foi abordada esta problemática. Neste constava a obrigatoriedade da existência, nos consultórios dentários, de vários fármacos e equipamentos de emergência. No entanto, em outubro de 2009, este Decreto-Lei foi revogado, tendo sido substituído pela Portaria n ${ }^{\circ}$ 268/2010 de 12 de maio10, onde consta que o único equipamento de emergência médica obrigatório é um "equipamento de ventilação manual, tipo ambú".

Equipamentos de emergência para consultórios dentários ${ }^{9}$ :

Equipamentos: • Estetoscópio; • Esfingmomanómetro; - Garrafas de oxigénio portáteis; • Ressuscitador (ambú); • Abre-bocas helicoidal; • Tubos de Guedel (Mayo); • Tubos orotraqueais ( $\mathrm{n}^{\mathrm{o}} 5$ a 8 ); • Pinça de tração da língua; • Aspirador de vácuo.

Descartáveis: • Garrote; • Seringas de 2cc, 5cc, $10 \mathrm{cc}$ e 20cc; • Agulhas no 19 e 21; • Cateteres venosos no 20 e 22; • Bisturi; • Tesoura; $\bullet$ Compressas esterilizadas; • Sistemas de soros; • Luvas cirúrgicas; • Gaze parafinada; - Suturas; o Algodão em rama; • Adesivo hipoalérgico; • Cânulas de aspiração; • Kit de ventimask.

Fármacos: • Soro fisiológico.

Para além deste equipamento enumerado, artigos sugerem a importância de ter um desfibrilador automático externo, cânulas nasais, magil fórceps e um relógio de parede com contador de segundos ${ }^{8}$.

Ocorrências de Emergências Médicas em Consultório Odontológico, e Relações Éticas e Legais do Cirurgião-dentista

O prontuário fornece ao profissional informações que ajudarão no diagnóstico, planejamento, execução e acompanhamento do tratamento odontológico ${ }^{11-12}$ e para o setor jurídico, o prontuário oferece dados para acusação ou defesa judicial $^{13}$.

Situações de emergência podem ocorrer antes, durante ou após o tratamento odontológico, mas podem ser prevenidas com a avaliação do estado geral de saúde do paciente e adoção de medidas preventivas simples, que aumentem a segurança clínica no atendimento. A realização de uma anamnese criteriosa é fundamental para a prevenção dessas ocorrências. Além disso, o profissional deve estar preparado para prestar os primeiros socorros, que incluem no mínimo, o Suporte Básico de Vida, que é um procedimento que vai garantir a ventilação pulmonar e a circulação sanguínea do paciente até que o mesmo receba o socorro médico especializado14.

Apesar da Odontologia no Brasil não ser uma especialidade médica, como é em alguns países da Europa, o cirurgião-dentista não tem menos responsabilidade que o médico pela vida de seu paciente, principalmente quando este está sob seus cuidados. O cirurgião-dentista não deve ter apenas responsabilidade em relação à saúde bucal, uma vez que essa não pode ser separada da saúde geral ${ }^{15}$.

O Código de Ética Odontológica relata no capítulo III Dos Direitos e Deveres Fundamentais dos Profissionais Art.5, inciso V: "zelar pela saúde e pela dignidade do paciente". A Consolidação das Normas para Procedimentos nos Conselhos de Odontologia de 2005 relata no capítulo II - Atividades Privativas do Cirurgião-Dentista - Art.4º, parágrafo $1^{\circ}$, inciso II: "prescrever e aplicar especialidades farmacêuticas de uso interno e externo indicadas em Odontologia", inciso VIII: "prescrever e aplicar medicação de urgência no caso de acidentes graves que comprometam a vida e a saúde do paciente". A legislação confere a responsabilidade pelo tratamento emergencial, mas muitas faculdades não ensinam este tópico ${ }^{16}$.

Segundo o Código Penal, qualquer pessoa pode prestar serviço de Suporte Básico de Vida, estando habilitada para isso. O cirurgião-dentista como profissional da saúde é inteiramente responsável por zelar da saúde de seu paciente, devendo estar capacitado para qualquer situação que possa vir ocorrer ${ }^{17}$.

\section{Protocolo de Avaliação para Primeiro Atendimento de Emergência}

Segundo a American Society of Anesthesiologists18, os pacientes devem ser avaliados pelo seu estado físico e categorias de risco médico.

O termo "Ficha Clínica" foi durante muito tempo utilizado para designar o nome de toda a documentação odontológica, mas considerando os aspectos éticos, legais e clínicos, o termo torna-se impróprio, devido ao grande número de informações que se deve ter sobre o paciente. Sendo assim, o conceito mais apropriado para a documentação odontológica passa a ser Prontuário Odontológico, pois este, junto com as informações referentes ao atendimento do paciente (ficha clínica), inclui toda a documentação que envolve o processo de atendimento $^{12,19}$. Nesse contexto, a ficha clínica passa a ser apenas um dos componentes do prontuário odontológico.

O cirurgião-dentista deve ter os conhecimentos técnicos sobre os protocolos de emergência, que incluem sinais vitais, nível de consciência, comprometimento neurológico, para que em seguida ocorra a orientação, o diagnóstico e o encaminhamento ao serviço especializado ${ }^{20}$. 
Qualquer artéria acessível consegue-se a verificação da mesma, que se resume nos batimentos por minuto. Os locais mais aferidos são o pulso carotídea (abaixo do ângulo da mandíbula) e a artéria radial (posição distal e central do pulso). Sendo a normalidade variando de 60 a 100 batimentos por minuto. Dessa forma segue-se os sinais e sintomas e conduta diante de uma parada cardíaca em consultório odontológico $^{21}$ :

Parada cardíaca: 1. Ausência de pulso ou pressão sanguínea; 2. Parada repentina da respiração (apneia); 3. Cianose; 4. Pupilas dilatadas.

Tratamento: 1. Vias aéreas - levante o queixo do paciente, desobstrua as vias aéreas, se necessário, e observe a respiração; 2. Respiração - inicie ressuscitação boca-a-boca, dê dois sopros rápidos iniciais, faça intubação endotraqueal e aplique oxigênio (pressão positiva de oxigênio) ${ }^{22}$.

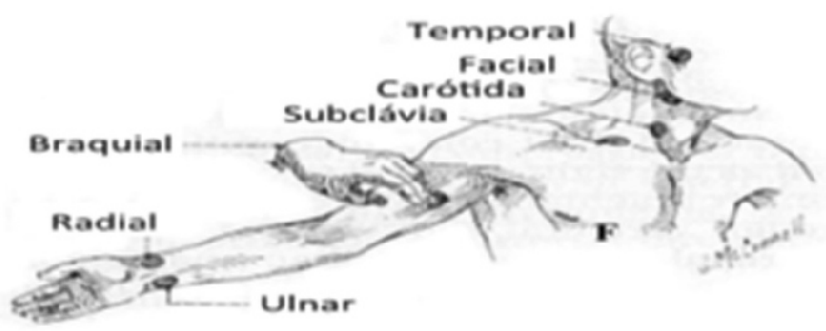

Figura 1 - Localização das artérias para avaliação da pulsação ${ }^{23}$.

A respiração é um ato de inspiração e expiração. Idealmente, a inspiração é realizada pelo nariz e a expiração pela boca. A frequência respiratória normal do adulto varia entre 12 - 20 movimentos respiratórios por minuto. Para essa mensuração deve-se verificar a expansão da caixa torácica durante a respiração. E em uma criança, os níveis de normalidade, variam de 16 - 25 movimentos respiratórios por minuto ${ }^{24}$.

Parada Respiratória

Causas: 1. Obstrução física das vias aéreas (língua ou objeto estranho); 2. Apneia induzida por medicamento.

Sinais e sintomas: 1. Cessação da respiração; 2. Cianose.

Tratamento: 1. Coloque o paciente na posição supina; 2. Mantenha as vias aéreas livres inclinando a cabeça do paciente para trás e removendo a obstrução, se possível; se não for possível, faça a manobra de Heimlich; 3. Chame o serviço de emergência médica; 4 . Ventile o paciente 12 a 15 vezes por minuto ${ }^{24}$.

Principais Síndromes Emergenciais que Podem Ocorrer no Consultório Odontológico

\section{Sistema Circulatório}

Síncope/Lipotímia

Por sua vez, a síncope é classicamente definida por uma perda total, transitória e rápida de consciência, seguida de recuperação espontânea. É um problema comum, que afeta um terço das pessoas durante a vida, tendo uma taxa de ocorrência de $30 \%{ }^{25}$.

A lipotímia é um mal-estar passageiro, caracterizado por uma sensação angustiante e eminente de desfalecimento, com palidez, sudorese, zumbido, visão turva, pulso fraco e queda da pressão arterial onde, raramente, há perda total de consciência ${ }^{26}$.

Perante um quadro de síncope, o dentista deve cessar de imediato o tratamento dentário, remover todos os objetos da boca, avaliar o grau de consciência do paciente e colocálo em posição supina com os membros inferiores levemente elevados em relação à cabeça/coração (10 a 15 graus). Deve-se estender a cabeça para trás de forma a circulação de ar ser mais eficaz e, em seguida, avaliar a permeabilidade da via aérea, a respiração e a circulação sanguínea e aguardar 2 a 3 minutos até a recuperação do paciente. No caso de pacientes grávidas, estas devem ser colocadas em posição supina, seguida de rotação para a esquerda ${ }^{27}$.

\section{Crise Hipertensiva}

Caracterizada pela elevação da pressão arterial sistólica e/ou diastólica, dependente de uma predisposição genética ou fatores de risco, tais como obesidade, sedentarismo, ingestão excessiva de sal, álcool, tabagismo, estresse, doença renal, entre outros ${ }^{28}$.

Uma vez diagnosticado eventos que caracterizem uma crise hipertensiva como elevação da pressão arterial, cefaléia, epistaxe, hemorragia gengival após manipulação, tontura, mal-estar, confusão mental e distúrbios visuais, deve-se interromper o atendimento imediatamente, colocar o paciente em posição confortável, monitorar seus sinais vitais e tranquilizá-lo, além de administrar captopril ( 25 a $50 \mathrm{mg}$ ), por via sublingual. Cessada a crise o paciente deve ser encaminhado o mais rápido possível para avaliação médica ${ }^{29-31}$.

\section{Angina Pectoris}

É definida como uma dor torácica retroesternal transitória, ocasionada pela diminuição regional do fluxo sanguíneo coronário quando o trabalho cardíaco e demanda de oxigênio excedem a capacidade do sistema arterial coronariano de fornecer sangue oxigenado. Dentre os principais sintomas, a dor ou desconforto no peito é o principal, sendo descrito como um "esmagamento ou queimadura", acompanhado de sudorese aumentada, palidez e agitação ${ }^{1}$.

Controlada a crise, cerca de 2 a 3 minutos, o paciente deve ser encaminhado para avaliação médica. Porém havendo persistência dos sintomas, pode tratar-se de um quadro mais grave, o infarto do miocárdio, devendo ser solicitado serviço médico de urgência32.

Infarto do Miocárdio

Clinicamente, apresenta-se como uma dor severa retroesternal semelhante à angina pectoris, porém de maior 
intensidade, podendo se refletir para outras áreas (nuca, braço esquerdo e mandíbula), seguida de náuseas, palidez, perda de consciência, palpitação, sudorese e cianose das mucosas (decorrente da redução do fluxo sanguíneo) ${ }^{33}$.

A principal causa, na maioria dos casos, deve-se a placas ateromatosas que obstruem parcial ou totalmente um dos ramos da artéria coronária ${ }^{34}$.

A primeira conduta é interromper o tratamento e colocar o paciente em posição confortável (cadeira odontológica semi-reclinada), afrouxar suas roupas e mantê-lo calmo. Enquanto aguarda o serviço médico de urgência, o cirurgião-dentista deve monitorar os sinais vitais do paciente (respiração, pulso, pressão arterial) ${ }^{26}$.

\section{Sistema Endócrino}

Hipoglicemia

É caracterizada por níveis plasmáticos de glicose iguais ou inferiores a 40 miligramas por decilitro de sangue. Representa uma ameaça à vida, podendo ocorrer em indivíduos diabéticos e não-diabéticos ${ }^{26}$.

Os sinais e sintomas da hipoglicemia se desenvolvem rápida e progressivamente, porém caracteriza-se inicialmente por náuseas, sensação de fome e alteração no humor e espontaneidade. Em seguida ocorre sudorese, taquicardia, aumento da ansiedade, não cooperação e agressividade. Posteriormente, em fase tardia, são comuns convulsões, perda de consciência, diminuição da pressão arterial e temperatura corporal ${ }^{1}$.

Para a avaliação da glicose sanguínea, é comumente utilizado o método da avaliação da glicemia capilar, através de um glicosímetro. Esta técnica consiste na picada de uma extremidade (normalmente um dedo), através de uma ponta a que chamamos "lanceta", para obtermos uma gota de sangue, sendo esta colocada numa tira reagente que será inserida e avaliada pelo glicosímetro, que indicará o valor da glicose sanguínea ${ }^{19}$.

\section{Sistema Nervoso}

Convulsão e Epilepsia

Desordem na função cerebral normal na qual há um desligamento momentâneo das sinapses, caracterizada por períodos de atividade motora, fenômenos sensoriais e mudanças de comportamento e consciência. Normalmente se apresentam com contrações musculares sustentadas, intermitentes, com períodos curtos de relaxamento e perda de consciência. Embora possa ser de natureza idiopática também é decorrente de traumas físicos, estresse emocional, febre alta, abstinência de drogas psicotrópicas e álcool e overdose de anestésicos ${ }^{26}$.

Caso aconteça um episódio de convulsão no consultório odontológico, deve-se interromper imediatamente o atendimento, remover objetos da boca do paciente, evitando assim sua deglutição acidental, colocá-lo em posição supina, deixando as vias aéreas superiores desobstruídas e inclinar sua cabeça para o lado a fim de que o vômito ou saliva não sejam broncoaspirados. Além disso, monitoram-se seus sinais vitais e aguarda o fim da crise ( 3 a 5 minutos) 1,32 .

\section{Acidente Vascular Cerebral}

Vários são os fatores de risco para o acidente vascular cerebral, podendo ser elucidados no momento da anamnese. Entre eles estão: hipertensão arterial, cardiopatias, diabetes, níveis elevados de colesterol no sangue, hiperglicemia, obesidade, tabagismo, etilismo e uso de contraceptivos orais ${ }^{17}$.

Seus sinais e sintomas são bastante variados, dependendo da área cerebral afetada, no entanto a fraqueza é o sintoma mais comum, podendo estar associada à dormência em um dos membros ou face. A fala pode também apresentar-se alterada, acompanhada de cefaléia, diminuição e/ou perda de consciência e vômitos ${ }^{26}$.

Em casos de indícios que caracterizem um acidente vascular cerebral durante o atendimento odontológico, o profissional deve interromper o tratamento e ligar imediatamente para o serviço médico de urgência enquanto mantém respiração e circulação do paciente, colocando-o em posição confortável, além de monitorar seus sinais vitais ${ }^{26}$.

\section{CONCLUSÃO}

As ocorrências de emergências médicas estão cada vez mais frequentes nos consultórios odontológicos e que os cirurgiões dentistas não se mostram adequadamente preparados para enfrentar essas situações.

Existe na Odontologia o amparo legal para a atuação do cirurgião-dentista frente às emergências que possam ocorrer em seu consultório odontológico. A Lei n ${ }^{\circ}$ 5081/66, que regulamenta o exercício profissional dos cirurgiõesdentistas.

A preparação do consultório, do profissional e de seu pessoal, é um dos fatores mais importantes no controle das tais emergências. Essa preparação deverá incluir: profissional e equipe devidamente preparadas para este tipo de situações; pronto acesso a um serviço médico especializado; equipamentos e medicamentos necessários para tratar os pacientes que apresentem uma emergência médica.

Quanto às implicações éticas e legais, fica claro que o cirurgião-dentista é responsável por zelar pela vida de seu paciente, pois é um profissional da área da saúde, mesmo que não tenha conhecimento suficiente tem, portanto a obrigação de socorrer qualquer indivíduo que venha sofrer alguma situação de emergência.

Finalizando, é importante frisar que o cirurgiãodentista somente será condenado, e consequentemente, punido, se ficar devidamente comprovado, sem sombra de dúvidas, que houve um dano, causado por ele, e que agiu 
com culpa (negligência, imprudência, imperícia) ou dolo. $\mathrm{Na}$ situação ora analisada teria que ficar comprovado que agiu com culpa ou dolo ao não prestar os primeiros socorros a seu paciente em caso de uma emergência. Como regra geral em quaisquer emergências médicas, o melhor método para tratá-las é preveni-las. Uma boa anamnese pode evitar até $90 \%$ das emergências.

\section{REFERÊNCIAS}

1. Monazzi MS, Prata, DM, Vieira, EH, Gabrielli MAC, Carlos E. Emergências e urgências médicas: como proceder? RGO. 2001;49(1):7-11.

2. Emery RW, Guttenberg AS. Management priorities and treatment strategies for medical emergencies in the dental office. Dent Clin North Am. 1999;43(3):401-19.

3. Marzola C, Griza GL. Profissionais e acadêmicos de odontologia estão aptos para salvar vidas? J Assessoria Odontol. 2001

4. Canesin MF, Timermam S, Marques FRB, Ferreira D, Moura IR. "Tempo é vida" - um dever de conscientização da morte súbita. Arq Bras Cardiol. 2005;84(6):441-2.

5. Silva EL, Nogueira AJS. Suporte básico de vida: Diferencial no atendimento ou responsabilidade legal odontológica? Rev Assoc Paul Cir Dent. 2006;60(5):392-4.

6. Shampaine GS. Patient assessment and preventive measures for medical emergencies in the dental office. Dent Clin North Am. 1999;43(3):383-400.

7. Andrade ED, Ranali J. Emergências médicas em odontologia. 2 ed. São Paulo: Artes Médicas; 2004

8. Rosenberg M. Preparing for medical emergencies: the essencial drugs and equipment for the dental office. J Am Dent Assoc. 2010;141:14-9.

9. Decreto-lei $n^{\circ} 233 / 2001($ Aug 25, 2001)

10. Decreto-lei revogado $\mathrm{n}^{\circ} 233 / 2001$ (Aug 25, 2001), Portaria $\mathrm{n}^{\circ}$ 268/2010 (May 12,2010).

11. Németh G, Paula LM, Varella MA, Angeletti P. Prontuário odontológico na clínica de cursos de odontologia [Internet]. [cited 2017 Sept 1]. Available from: http://www.abeno.org.br/anais/anais2001.htm-148.

12. Almeida CAP, Zimmermann RD, Cerveira JGV, Julivaldo FSN. Prontuário odontológico: uma orientação para o cumprimento da exigência contada no inciso VIII do art. $5^{\circ}$ do Código de Ética Odontológico [Internet]. [cited 2017 Sept 1]. Available from: http://www.crogo.org.br/art005/prontuario2004.pdf.

13. Louzã JR. Documentos médicos: aspectos éticos e legais. In: Segre M, Cohen C. Bioética. 3 ed. São Paulo: Editora da Universidade de São Paulo; 2002. p. 201-15.

14. Rotta RFR, Freire MCM, Nunes CABCM, Lopes CSM, Nascimento LP, Costa TA. Emergências médicas em odontologia: nível de instrução e capacitação dos cirurgiões dentistas no estado de Goiás. RevABO Nac. 2007;15(3):159-65.
15. Liporaci Jr. J. Emergências médicas em odontologia. Apostila do curso de emergências médicas em odontologia. Ribeirão Preto; 2006.

16. Resolução 042, Código de Ética Odontológica (May 20, 2003).

17. Caputo IGC. Emergências médicas em consultório odontológico: Implicações éticas e legais para o cirurgião-dentista [dissertação]. Piracicaba: Faculdade de Odontologia, Universidade de Piracicaba; 2009.

18. American Society of Anesthesiologists. Classification of physical status [Internet]. [cited 2017 Sept 4]. Available from: htpp://www.asahq.org/clinical/physicalstatatus.htm.

19. Conselho Regional de Odontologia de Minas Gerais. Manual de orientação profissional. Belo Horizonte: CRO-MG; 2000.

20. Evandro, F. Trauma: a doença do século. São Paulo: Atheneu; 2001. p. 1450.

21. Porto CC. Semiologia médica. 5 ed. Rio de Janeiro: Guanabara Koogan; 2005.

22. Little JW, Falace DA, Miller CS, Rhodus NL. Manejo odontológico do paciente clinicamente comprometido. 7 ed. Rio de Janeiro: Elsevier; 2008.

23. Pazin-Filho A. Parada cardiorrespiratória (PCR). Medicina (Ribeirao Preto). 2003;36:163-78

24. Henriques F, Santos C, Amaral A. Monitorização de parâmetros vitais. In: Técnicas de enfermagem I. 3 ed. Coimbra: Formasau; 2004. p. 7-47.

25. Elguindy M. Syncope. Heart Mirror J. 2007;1(2):82-8.

26. Resende RG, Lehman LFC, Miranda BB, Cunha JF, Costa MLT, Gomez RS, et al. Complicações sistêmicas no consultório odontológico: parte I. Arq Odontol. 2009;45(1):44-50

27. Lúcio P, Barreto, R. Emergência médica no consultório odontológico e a (in)segurança dos profissionais. Rev Bras Cienc Saude. 2012;16(2):267-72.

28. Monego ET, Jardim PC. Determinantes de risco para doenças cardiovasculares em escolares. Arq Bras Cardiol. 2006;87(1):37-45.

29. Gomez RS, Maia DMF, Lehman LFC, Santoro DR, Azeredo P, Castro WH. Emergências médicas no consultório odontológico. Rev CROMG. 1999;5(1):4-10.

30. Chapman NPJ. An overview of drugs and ancillary equipment for the dentists emergency kits. Aust Dent J. 2003;48(2):130-2.

31. Montan MF, Cogo K, Bergamaschi CC, Volpato MC, Andrade ED. Mortalidade relacionada ao uso de anestésicos locais em odontologia. RGO. 2007;55(2):197-202.

32. Andrade ED, Ranali J. Emergências médicas em odontologia. 3 ed. São Paulo: Artes Médicas; 2011

33. Barros MNF, Gaujac C, Trento C, Andrade MCV. Tratamento de pacientes cardiopatas na clínica odontológica. Rev Saude Pesqui. 2011;4(1):109-14

34. Munoz MM, Soriano YJ, Roda RP, Sarrión G. Cardiovascular diseases in dental practice. Practical considerations. Med Oral Patol Oral Cir Bucal. 2008;13(5):296-302. 